ISSN: 0210-7287

DOI: http://dx.doi.org/10.14201/161620199131149

\title{
UN DISCÍPULO OULIPIANO DE PIERRE MENARD
}

\section{An Oulipian Pierre Menard's Disciple}

\author{
Manuel J. PÉREZ PÉREZ \\ Universidad de Sevilla \\ perezperezmj@yaboo.es
}

Recibido: junio de 2019; Aceptado: septiembre de 2019; Publicado: diciembre de 2019

Ref. Bibl. MANUEL J. PÉREZ PÉREZ. UN DISCÍPULO OULIPIANO DE PIERRE

MENARD. 1616: Anuario de Literatura Comparada, 9 (2019), 131-149

RESUMEN: Pierre Menard, el personaje del cuento de Borges posteriormente reelaborado por Michel Lafon en su novela Une vie de Pierre Ménard, se encuentra agazapado detrás de algunos de los procedimientos compositivos empleados por los autores del OuLiPo, como el "plagio por anticipación» o las técnicas de escritura restrictiva como forma de expansión textual. Basándonos en una concepción dinámica y paródica de la literatura, en la noción de intertextualidad y en la capacidad de proyección del personaje en otros textos, en el presente estudio analizamos uno de sus más peculiares desdoblamientos, el que se produce en el relato de Georges Perec Le voyage d'hiver. Partimos de las afinidades tanto formales como conceptuales que presentan las tres obras para finalmente asistir a la paulatina disgregación de los dos personajes en la propia narración, revelando así su condición de mero artificio textual.

Palabras clave: Jorge Luis Borges; Georges Perec; Michel Lafon; Pierre Menard; OuLiPo; intertextualidad.

ABSTRACT: Pierre Menard, the character of Borges' tale later reworked by Michel Lafon in his novel Une vie de Pierre Ménard, is hidden behind some of the compositional procedures used by the authors of the OuLiPo, such as the 
"plagiarism for anticipation" or the constrained writing techniques as a form of textual expansion. Basing on a dynamic and parodic conception of literature, on the notion of intertextuality and on the capacity of projection of the character in other texts, in the current study we analyze one of his most peculiar unfolding, which is produced in the narration of Georges Perec Le voyage d'hiver. We start from the affinities both formal and conceptual that the three works present to finally attend the gradual disintegration of the two characters in the narration itself, thus revealing its condition as a mere textual artifice.

Key words: Jorge Luis Borges; Georges Perec; Michel Lafon; Pierre Menard; OuLiPo; Intertextuality.

\section{INTRODUCCIÓN}

Emerson dijo que una biblioteca es un gabinete mágico en el que hay muchos espíritus hechizados (Borges 1989, 1: 254)

Cronológicamente, aunque una perspectiva lineal del tiempo resulta poco afortunada cuando se habla del Ouvroir de littérature potentielle (OuLiPo), este ensayo comienza y termina con Pierre Menard ${ }^{1}$, con el personaje creado por Borges en su cuento "Pierre Menard, autor del Quijote» (Ficciones, 1944) y posteriormente recreado por Michel Lafon en su novela Une vie de Pierre Ménard (2008) ${ }^{2}$. En medio se sitúa Hugo Vernier, el evanescente protagonista de Le voyage d'biver, una breve nouvelle de Georges Perec publicada en 1983 en el número 193 de Le Magazine littéraire, un año después de la muerte del escritor. En realidad, no comienza con uno ni termina con otro, sino que establece determinados vínculos de reciprocidad entre las tres narraciones mencionadas y plantea unas relaciones

1. Salvo en las citas en francés, utilizaremos la forma española "Menard", sin el acento agudo de su forma francesa, Ménard.

2. Innumerables son los estudios sobre el cuento de Borges. Tan abarcadora ha sido su influencia desde su publicación hace ya ochenta años; "Pierre Menard, autor del Quijote» apareció por primera vez en la revista Sur en 1939. En cuanto a su relación con la novela de Michel Lafon y debido a su todavía relativa condición de novedad (apareció en Francia en 2008 en la editorial Gallimard y fue traducida al español en 2010 por César Aira para la editorial Lumen) pocos han sido aún los acercamientos a esta, más allá de algunos breves artículos como los de Diego Vecchio (2009) o Camilo Bogoya (2015). El presente trabajo tiene su origen en un capítulo de mi tesis doctoral «Pierre Menard y el personaje en las biografías imaginarias (Lafon, Wilcock, Borges y Schwob)", de 2017. 
dinámicas de intertextualidad (Alazraki 1984, 281-302; Guillén 2005, 287291) en las que descubrimos numerosas afinidades, variaciones, superposiciones, subversiones, desdoblamientos y plagios por anticipación que resaltan el carácter abierto y vital de las obras, su condición transgresora y su disposición a un diálogo constante y enriquecedor ${ }^{3}$.

La importancia que Borges concede a la lectura, el concepto de re-escritura $^{4}$ (estrechamente ligado al de intertextualidad), la decisiva aportación basada en la idea de la creación de los propios precursores, la concepción de la literatura como falsificación (todo ello anticipo de teorías y escuelas posteriores con un peso considerable en el desarrollo de la literatura en el siglo xx como la estética de la recepción, la filosofía de la deconstrucción o el concepto oulipiano del "plagio por anticipación") configuran, junto con el tema del doble, las reflexiones sobre identidad y autoría y la disolución de los límites que separan ficción de realidad, el corpus metaficcional necesario para comprender los mecanismos que operan en la gestación de estas obras y el diálogo que mantienen dentro de un marco supranacional de la literatura, según la terminología de Claudio Guillén.

¿Quién es Pierre Menard? El cuento «Pierre Menard, autor del Quijote» surgió como una burla expresa del autor de la excesiva afectación de la crítica francesa, en especial de Paul Valéry y Paul Groussac. Para Michel Lafon su primera intención era satírica $(1993,96)$. Con el paso del tiempo y considerando que cualquier texto literario que se precie es por su inherente condición de obra abierta susceptible de devenir en algo que va más allá de las intenciones iniciales del autor, el cuento de Borges ha ido adquiriendo diversas interpretaciones según las diferentes perspectivas desde la que ha sido abordado. Para Genette, por ejemplo, Pierre Menard se vincula con la parodia y la intertextualidad, para Blanchot con los avatares de la traducción, para Lem con la ciencia ficción (Tacca 1998, 725)5. Tal es la propensión

3. Así atendemos a relaciones intertextuales y no de influencia, ya que de acuerdo con Claudio Guillén $(2005,288)$ el concepto de influencia superponía lo biográfico a lo textual y por ser de índole genética se antojaba ilimitado, difícil de abarcar, incapaz de delimitar las claves fundamentales y precisas que conectan a una obra con otras.

4. «Re-escribir no consiste en duplicar, en agregar algo más tras una sofisticada y auto-consciente manipulación de códigos, géneros o modos narrativos; re-escribir es escribir "tras" haber ya firmado la post-data de toda obra posible. Es, precisamente, el rumor de esta "escritura invisible" que hace que el texto de Borges sea una máquina altamente inestable, como es el caso del monstruoso "Libro de Arena", en el que el lector no puede localizar la misma página más de una vez» (Riera 2005, 223).

5. «En nuestra opinión, se trata cabalmente de una ficción. En todo caso, de una ficción cuya sustancia o tema narrativo es el ensayo (más precisamente, la "nota" bibliográfica, el comentario crítico o erudito) o que adopta (paródicamente) la forma del ensayo. Pero el 
camaleónica del personaje ideado por Borges y su facilidad de adecuación a otros contextos. En un estudio anterior (Pérez Pérez 2019, 173-191) asistimos a la doble condición de personaje-artificio textual de Pierre Menard y a su paulatina disgregación en la obra, revelando así su carácter proteico e indeterminado. Aquí pondremos una mayor atención en las técnicas compositivas del OuLiPo, intentado mostrar su deuda con el personaje del cuento de Borges, considerando a su vez la reencarnación de dicho personaje en la novela de Lafon. Incidiremos en la consideración del papel activo de la lectura como apropiación. Todo texto es primero absorción y luego transformación ${ }^{6}$. "Escribir es releer un texto anterior" (Alazraki 1984, 281) y en la lectura todos los tiempos confluyen en el presente.

Sesenta y cuatro años después de la publicación de Ficciones se edita en Francia la novela de Michel Lafon. Si Borges escribió una ficción disfrazada de necrológica, Lafon hace lo propio camuflando esta vez su ficción tras la apariencia de una biografía. Si Borges irrealizaba a su personaje mediante la renuncia de este a publicar y reclamaba su condición de mero artificio literario, Lafon le restituye a Menard un pasado, una memoria, realizándolo y relegando así, parodia y homenaje a un tiempo, al Borges autor a la condición de personaje, sugiriendo la inestabilidad de las fronteras entre ficción y realidad y la invasión de la segunda por la primera.

En lo que concierne a esta investigación, «Pierre Menard, autor del Quijotes anticipa un método que luego será profusamente desarrollado por el taller de literatura potencial, el de la literatura de las restricciones o trabas. Porque para Menard escribir es dotar de un sentido nuevo a un producto ya existente, a través de la limitación que supone repetir palabra por palabra el modelo, lo que paradójicamente lo libera y le otorga una nueva dimensión significativa. El Quijote de Menard es un calco sintáctico del de Cervantes, pero difiere de este por su nueva adecuación contextual. Por su parte, Hugo Vernier, el protagonista de Le voyage d'hiver, es el autor de un hipotexto perdido y disperso entre las obras más relevantes de la poesía francesa del siglo XIX, el esbozo de un autor indefinido donde parecen aglutinarse las identidades de Germain Nouveau, Tristan Corbière, Villiers y Banville, Rimbaud y Verhaeren, Léon Bloy, Mallarmé, etc. Un discípulo secreto de Menard, el personaje de un relato que, como el cuento de Borges o la novela de Lafon, oscila entre la parodia y la melancolía, entre la pesquisa policial y

relato es plenamente un cuento, una ficción: la fantasía, el humor, la ironía resultan evidentes. Es un cuento intelectual que juega con los hábitos y remeda los vicios del ensayo, la crítica y la erudición» (TACCA 1998, 728).

6. "Tout texte se construit comme mosaïque de citations, tout texte est absorption et transformation d'un autre texte» (KRISTEVA 1969, 146). 
la metaficción. Un relato de fantasmas encubierto bajo la apariencia de una investigación literaria y vital. Un juego de desvíos y mistificaciones y una burla del exceso erudito de la crítica; una desintegración del autor que sugiere la imposibilidad de escribir obras originales.

\section{Pierre Menard y Hugo Vernier. El autor oculto en el palimpsesto}

En qué ayer, en qué patios de Cartago, cae también esta lluvia.

(Borges 1992, 116)

"Toda obra es el espejo de otra», escribe Georges Perec $(2008,27)$ en $E l$ gabinete de un aficionado. El personaje Pierre Menard, de tanto reflejarse y dispersarse por otros textos, termina desapareciendo enredado en esa maraña textual. Lo mismo sucede, como veremos, con uno de sus más peculiares descendientes. Hay evidentes conexiones entre el personaje-escritor de Nîmes y su proyecto de (re)escribir el Quijote y los métodos de composición utilizados por los escritores del OuLiPo. Nos referimos a las técnicas de escritura limitada, la literatura de las restricciones (contraintes) ${ }^{8}$, que Georges Perec y varios de sus colegas aplicaron en la elaboración de sus obras a partir de los años 60 del siglo pasado, cuando Raymond Queneau y François Le Lionnais fundaron el grupo. Advertimos ciertas correspondencias entre la revolucionaria idea de Menard y la limitación compositiva de La disparition, la novela en la que Perec prescinde de la vocal $e$, la más común en francés. El propio Menard representa un lipograma completo, una ausencia, un asunto no terminado, un misterio que oculta otros misterios y

7. "Quienes han insinuado que Menard dedicó su vida a escribir un Quijote contemporáneo, calumnian su clara memoria. No quería componer otro Quijote -lo cual es fácil-, sino el Quijote. Inútil agregar que no encaró nunca una transcripción mecánica del original; no se proponía copiarlo. Su admirable ambición era producir unas páginas que coincidieran -palabra por palabra y línea por línea- con las de Miguel de Cervantes» (BORGES 1989, 1: 446).

8. La contrainte, traba o restricción en español, es un concepto fundamental para los oulipianos que podemos definir como la regla que impone y determina una estructura literaria. La restricción realza, paradójicamente, la creatividad del lenguaje, lo agudiza, le otorga mayor libertad al obligarlo a establecer conexiones insólitas entre las palabras. "Así, escribe con trabas quien crea un poema ajustándose a la forma del soneto; pero la misión de los oulipianos, que se definen como "ratas que construyen el laberinto del que se proponen salir", es la creación de nuevas -y complejas- trabas que exploten al máximo las posibilidades del lenguaje» (MoHÍNo SÁNCHEZ 2004, 248). 
que admite tantas interpretaciones como lecturas. Pero si verdaderamente tenemos que mencionar un doble de Menard, una desviación a posteriori en la que se reflejan las obsesiones del relato de Borges, anterior a la novela de Lafon y por tanto precursora del segundo Menard, este es sin duda Hugo Vernier, quien constituye junto al concepto oulipiano del "plagio por anticipación» un paso más en la poética inaugurada con "Pierre Menard, autor del Quijote».

De las obras de Perec, más allá de ese enorme puzle que es La vie mode d'emploi, uno de los textos clave del último cuarto del siglo $\mathrm{xx}^{9}$, destaca una breve nouvelle titulada Le voyage d'biver ${ }^{10}$, cuyo protagonista, Hugo Vernier, guarda íntimas afinidades con Pierre Menard; así como el personaje en la sombra, Vincent Degraël, nos recuerda tanto a Maurice Legrand (el narrador de Une vie de Pierre Ménard) como al narrador sin nombre del cuento de Borges. La diferencia entre ambos reside en que tanto el personaje del relato de Borges como el de la novela de Lafon son a su vez los narradores principales del texto, mientras que en el relato de Perec es un narrador extradiegético quien nos cuenta las apasionantes pero infructuosas pesquisas iniciadas por el personaje secundario, Vincent Degraël, en busca de un autor fantasmagórico, el inefable Hugo Vernier. Vernier comparte con Menard su indeterminación y su doble función textual, irónica y simbólica ${ }^{11}$. Los procedimientos de composición del texto le sirven a Perec para reflexionar sobre la autonomía del lenguaje literario

9. «En todas las reflexiones sobre la novela francesa del último cuarto del siglo pasado consigue siempre colarse el nombre de Georges Perec. Sus perfiles son tan variados que podría oficiar de progenitor de varias familias de novelistas. Cuatro rasgos a modo de ejemplo: con Las cosas inventó un tipo de novela sociológica de personajes fríos y sosos que los exitosos Modiano o Echenoz siguen cultivando hoy. Como oulipiano y formalista dio una lección magistral en La disparition, donde la letra e -la más utilizada en francés- desaparece lipogramáticamente durante toda una novela para luego reaparecer desplazando a todas las otras vocales en la novela siguiente: Les revenentes. Como visionario del mestizaje de géneros concibió $W$ ou le souvenir d'enfance, donde se alternan los capítulos de ficción y de autobiografía Y como moderno émulo de la Comedia bumana de Balzac -o, dicho de otro modo, como renovador de tradiciones- Perec escribió La vida, modo de empleo, vasto puzzle de vidas simultáneas que podría asemejarse a una polidimensional 13 rue del Percebe» (GAmoneda 2009, 44).

10. En 1983, con la ocasión de un número especial dedicado a Georges Perec, Le Magazine littéraire ( ${ }^{\circ}{ }^{\circ} 193$ ) publica la breve nouvelle titulada Le voyage d'hiver, anteriormente aparecida en el n. ${ }^{\circ} 18$ del boletín Hachette Informations (marzo-abril, 1980).

11. Perec se sirve de la ironía para establecer un vínculo de complicidad con el lector, un guiño para que este se sienta copartícipe en la elaboración de la obra desentrañando el significado implícito que se esconde en el texto. Se propone así un acercamiento lateral a las entrañas del relato, urdido de manera indirecta, resaltando su condición de simulacro y 
y sobre su capacidad para referirse a sí mismo. En este caso, la ironía disimula el trasfondo metaliterario, propone una subversión, o al menos un cuestionamiento, del canon establecido y reivindica la libertad de la literatura más allá de las modas, los nombres y las fechas. Plantea una visión no académica de la literatura. Al mismo tiempo reflexiona sobre la sinergia que conforman escritura y lectura y retoma la idea de Borges de que el autor crea sus propios precursores ("Kafka y sus precursores»): "La comunión entre el lector y el escritor es el reflejo de una comunión anterior entre el escritor, que, escribiendo, repite a otro escritor. [...] el lector no sólo inventa el texto que está leyendo, sino que simultáneamente entra en contacto con otra tradición, como si leer a un autor fuera leer al mismo tiempo a sus precursores» (Bogoya 2008, 29). Las condiciones contextuales que rodean el proceso de lectura son tan decisivas como las que circundan el proceso de escritura. Dichas condiciones interpretan y reubican el texto, manteniendo su pulsión interna y dirigiéndolo hacia zonas ignoradas en la fase germinal de su elaboración. Dislocan el contexto inicial para constituir nuevas condiciones y nuevos hábitos que implican la desaparición del autor (o al menos su invisibilidad) al devenir el texto siempre en algo distinto. En el relato de Perec, Vernier (como hiciera Menard con los tres capítulos del Quijote que se propone (re)escribir en el cuento de Borges) opera de manera invisible sobre el contexto. En "Pierre Menard, autor del Quijote», "la obra original es originada por la reseña que le hace eco, lo que debería existir antes no es más que un efecto retrospectivo» (Pauls 2004, 117-118).

Por otro lado, Perec representa a una generación de escritores más preocupada por el funcionamiento de los mecanismos de escritura que por el mensaje reflejado en el texto (o en todo caso considera que ambos son inseparables). La escritura se erige así en el motivo esencial de lo literario, no solo en su herramienta:

Cuando el escritor se interesa por el proceso de su propia escritura y de ello resulta una reflexión consciente y profunda, este escritor está en condiciones de añadir a su obra una trascendencia aún mayor y, en consecuencia, de abrir paso a la posibilidad de un cambio en la expresión escritural y literaria de dicha obra. Desde el momento en que el escritor trata de responder a las preguntas por siempre planteadas y si se producen respuestas que interesan directamente al porvenir de su escritura, esa actitud reflexiva relacionada con su trabajo nos presenta un escritor

reforzando por su atenuación aquello que permanece oculto, lo que emerge como esencial precisamente por decir lo contrario, el anverso de lo lingüísticamente manifiesto. 
nuevo y distinto: el escritor-escritor, aquel que proporciona la explicación del hecho de escribir al mismo tiempo que escribe (Camarero 1988, 90).

El argumento de la narración es el siguiente: poco antes del comienzo de la Segunda Guerra Mundial, un joven profesor de letras que prepara una tesis sobre la evolución de la poesía francesa de los Parnasianos a los Simbolistas, Vincent Degraël, es invitado a pasar unos días en una propiedad perteneciente a los padres de uno de sus colegas. En la biblioteca de dicha propiedad encuentra un volumen titulado Le voyage d'hiver, atribuido a un tal Hugo Vernier. El libro está escrito en primera persona y situado en una región imaginaria. Su estructura está dividida en dos partes claramente diferenciadas. La primera narra un viaje iniciático marcado por la fatalidad y caracterizado por una atmósfera sombría que recuerda los relatos góticos del siglo XIX. La segunda, la invisible, como sucede en el cuento de Borges con los tres capítulos del Quijote que Menard encara, la disimulada bajo las líneas de ese relato misterioso e inconcluso que funciona como pretexto del verdaderamente relevante, comprende una larga confesión que mezcla poemas y opiniones sobre literatura. Como señala Amelia Gamoneda (2004, 44), esta segunda parte del libro que Degraël tiene en sus manos comienza a producir en el lector el vértigo de las estructuras en abismo y funciona como reflejo del propio libro de Perec, el que nosotros hemos tenido entre las manos. Hemos experimentado así una sensación parecida a la de Vincent Degraël, ya que, si el libro de Hugo Vernier contiene una primera parte que parece constituir tan solo un pretexto para la segunda, tal vez la narración de Perec encierre a su vez una intención apenas sugerida al ocultar la reflexión literaria bajo el aspecto de un relato fantástico, como Borges la disfrazara de necrológica en su relato y Lafon hiciera lo propio disimulando su ficción bajo la apariencia de una biografía. Podemos afirmar entonces que los tres textos son, en última instancia, marcadamente autorreferenciales y que inciden directamente en la participación activa de la lectura en la elaboración de las obras y en el diálogo permanente entre ellas:

À peine eut-il commencé à la lire que Vincent Degraël éprouva une sensation de malaise qu'il lui fût impossible de définir précisément, mais que ne fit que s'accentuer au fur et à mesure qu'il tournait les pages du volume d'une main de plus en plus tremblante: c'était comme si les phrases qu'il avait devant les yeux lui devenaient soudain familières, se mettaient irrésistiblement à lui rappeler quelque chose, comme si à la lecture de chacun venait s'imposer, ou plutôt se superposer, le souvenir à la fois précis et flou d'une phrase qui aurait été presque identique et qu'il aurait déjà lue ailleurs; comme si ces mots [...] esquissaient une configuration confuse où l'on croyait retrouver pêle-mêle Germain Nouveau et Tristan Corbière, 
Villiers et Banville, Rimbaud et Verhaeren, Charles Cros et Léon Bloy (Perec 2013, 12-13).

Degraël reconoce las citas textuales desperdigadas en el libro de Vernier y piensa en un primer momento que este las ha copiado inconscientemente de los autores antes citados. Luego considera la posibilidad de una feliz coincidencia. Del mismo modo y continuando el juego especular, Perec se apropia de algunas citas de Mallarmé, Rimbaud y Verlaine. Esa interrelación del texto de Perec con otros textos encierra la tesis fundamental del relato: «la de la intertextualidad congénita de toda literatura» (Gamoneda 2004: 44), una idea recurrente en la poética del OuLiPo que remite de manera directa a Borges. Partiendo de otros autores que adopta como clásicos personales y a los que enriquece mediante su lectura, o sea, partiendo de la biblioteca, Borges crea una obra personal que trasciende sus propios límites. De igual modo Perec sugiere que el verdadero problema consiste en la imposibilidad de abandonar la Biblioteca, que no solo contiene el universo conocido o supuesto, sino todas sus alternativas, como ocurre en el mundo ficcional de Borges ${ }^{12}$. Porque para Borges no hay diferencia entre biblioteca y universo, «nosotros estaríamos en la biblioteca misma, es más, formaríamos parte de la biblioteca misma, y no podríamos salir de ella» (Eco 2002, 119).

Posteriormente asistimos perplejos, como Degraël, a un inesperado cambio de dirección: el investigador descubre que el libro de Vernier es de 1864 y que en esa fecha los autores mencionados no habían escrito aún tales versos. Por tanto, son ellos quienes han plagiado al misterioso Vernier. Lo que parecía un juego teórico sobre intertextualidad y autoría bascula hacia los parámetros del relato fantástico. Un único libro misterioso hecho con las frases de libros posteriores que ya contiene en su origen. Una dislocación del tiempo. Como un aleph donde se concentra simultáneamente toda la literatura, la anterior y la por venir. Aquí hace aparición el recurrente tema del doble y de la impostura. Mediante la máscara, ese artilugio intermedio entre el ser y la apariencia, el autor, escamoteando una imagen ajena como hace el impostor Tom Castro en el cuento de Borges incluido en su Historia universal de la infamia (1935), deviene en aquello en lo que se proyecta y que ya prefigura, se apropia de la obra por venir transformándola hasta hacerla suya, que es lo mismo que decir hasta hacerla anónima y liberarla de las ataduras del tiempo y de la autoría, "pues la

12. Como, entre otros muchos, sucede en el célebre cuento que abre el volumen Ficciones, «Tlön Uqbar, Orbis Tertius», en el que la ficción, el mundo imaginario o alternativo de Tlön, acaba invadiendo meticulosa e irreversiblemente la realidad. 
visión intertextual de la literatura supone su naturaleza vampírica o caníbal» (Gamoneda 2004, 44).

Distinguimos en el relato de Perec tres niveles: uno cómico, otro fantástico y un tercero teórico o metaliterario. Identidad y alteridad, parodia e impostura, como en "Pierre Menard, autor del Quijote", constituyen sus claves. Perec se burla de la gravedad de la crítica y de toda exégesis reduccionista. La obra subterránea, la oculta, la clandestina, permanecerá ignota para siempre, como si jamás se hubiera escrito, tan solo un proyecto, una vislumbre, una teoría. Esa obra que de forma parecida le escamotean a Menard sus contemporáneos en la novela de Lafon. En su investigación, Degraël pretendía la síntesis absoluta al sustituir, o condensar, a los grandes poetas franceses del XIX por un único nombre: Hugo Vernier. Un solo autor y una sola obra. Degraël, un poco como Legrand en Un vie de Pierre Ménard, ha dedicado su vida a la persecución de un fantasma.

Vernier ha elaborado un centón por anticipado con los versos de los célebres poetas a los que su misteriosa obra se adelanta y con los que más tarde se confundirá, despojándose así de su identidad primera, perdida para siempre en el palimpsesto manipulado por las escrituras posteriores.

En vano, Degraël dedica el resto de su vida a investigar sobre la misteriosa figura de Hugo Vernier con la intención de reivindicar su existencia y reclamar el papel silencioso pero decisivo que este autor ignorado tuvo en el devenir de la literatura francesa de finales del siglo XIX. No conseguirá jamás descubrir la identidad de ese autor desconocido porque es una metáfora del autor-lector inédito y anónimo que Borges sugiriera en su relato, una encarnación o un desdoblamiento del inasible Pierre Menard. Así, Le voyage d'hiver se convierte en una "antología premonitoria", un texto que oscila entre la reflexión poética y lo fantástico, un "plagio por anticipación ${ }^{13}$ (una de las claves de la poética oulipiana, íntimamente relacionada con la idea ya señalada de que todo gran escritor crea a sus precursores y del texto modificado por el paso del tiempo). Un libro hecho de otros libros, aglutinando en un solo autor -al que Perec pone nombre- las múltiples identidades que reconoce la historia de la literatura; un diálogo enriquecedor entre los libros, un intercambio y una apropiación. Lamentablemente, Dregaël descubre que el ejemplar que examinó en la casa de su colega fue destruido con el resto de la biblioteca durante un bombardeo. La

13. «Il nous arrive parfois de découvrir qu'une structure que nous avions crue parfaitement inédite, avait déjà été découverte ou inventée dans le passé, parfois même dans un passé lointain. Nous nous faisons un devoir de reconnaitre un tel état de choses en qualifiant les textes en cause de "plagiats par anticipation". Ainsi justice est rendue et chacun reçoit-il selon ses mérites» (OuLIPO 1973, 23). 
presencia ominosa de la guerra como contingencia imprevisible juega un papel decisivo en el proceso de disolución tanto de la obra como del autor, convirtiendo en anónimas las señas de identidad del individuo. De nuevo asistimos a la irrupción inesperada de la fatalidad. Vernier y su libro pasan a ser no más que cenizas, un vago rumor del pasado solo advertido por el no menos transitorio y esquivo Vincent Degraël. Del resto de ejemplares del libro, unos quinientos según las investigaciones de Degraël, no queda el menor rastro. Perversamente, el narrador sugiere que todos fueron voluntariamente destruidos por los mismos que se habían apropiado de su tesoro, en una conspiración contraria a la que asistimos en la novela de Lafon, donde el cometido de los congresales era crear, no destruir, un autor impersonal y anónimo. Irónicamente, esos que se empeñaron en borrar las huellas de Vernier para la posteridad son los que se referían a él como «V. H.», no Victor Hugo, sino Hugo Vernier, al que acudieron falazmente una y otra vez para componer sus mejores páginas. Esta es la parte humorística del relato, donde Perec, a la manera del Pierre Menard de Borges, introduce la chanza burlándose de la prolijidad de la novela decimonónica y de la fama atribuida a Victor Hugo:

El juego de siglas -tan característico de Perec- se completa con otra buena dosis de ironía iconoclasta: Degraël interpreta las conocidas y enjundiosas máximas de Rimbaud y Lautréamont como simples justificaciones de plagio: para él, "yo es otro» confiesa una autoría ajena. Y «la poesía debe ser hecha por todos, no por uno» aconseja la práctica plagiaria que el propio Lautréamont mismo adoptó. Hay sin duda una burla de toda la exégesis con que los críticos han acompañado siempre estas frases: Perec está pintando bigotes y cuernos a estas figuras señeras de la escritura de la alteridad. Y, de modo más general, observamos que su escaparate de figuras de teoría crítica va adquiriendo un aire degradado o inquietante (Gamoneda 2004, 44).

Dos son los procedimientos principales de composición propuestos por los escritores oulipianos: por un lado, utilizar nuevas formas o estructuras caracterizadas por los principios restrictivos utilizados como herramientas creativas y, por otro, descubrir y recuperar recursos olvidados o desapercibidos de la tradición, otro planteamiento este último que desciende directamente de la ya mencionada idea ampliamente desarrollada por Borges de la creación de los propios precursores. Es decir, establecer analogías inadvertidas con el pasado a partir de las lecturas posteriores. Revitalizar esas obras mediante la influencia de la posteridad, resaltando su condición anticipadora. Obras, como la de Vernier, supuestamente escritas para un tiempo futuro, lo que provoca el primer sobresalto al advertir la dislocación temporal. Del mismo modo, Perec viene a proponer que una 
estructura aparentemente inédita guarda en su interior ecos del pasado. Lo verdaderamente novedoso de un texto literario no es su argumento sino la adecuación a un contexto en principio extraño que descubre relaciones hasta entonces ignoradas o adormecidas. Se abre un nuevo espacio propio y exclusivo del texto donde novedad y tradición interactúan creando un objeto vivo y cambiante. Así, esta pirueta conceptual del plagio por anticipación, además de un guiño irónico sobre el canon establecido, contiene también un homenaje a la tradición. Es la irrupción de un nuevo punto de vista la que revitaliza una tradición agazapada en pos de nuevos desarrollos, como advertimos en el Quijote de Menard, condicionado por la lectura de William James y de Bertrand Russell. De ahí la transgresora y polémica idea de Borges al considerarlo más rico que el Quijote de Cervantes, ya que el segundo contiene nuevas perspectivas de lectura y, lo que es más importante, abre el camino a posibles lecturas futuras, resaltando así la relevancia de su indeterminación ${ }^{14}$. La historia de la literatura no es una línea recta en el tiempo, sino una espiral enriquecida mediante el diálogo sostenido entre lectura y tradición. Cada avance es también un retroceso. Menard y Vernier son los auténticos embajadores del plagio por anticipación. La literatura oulipiana es a la vez retroactiva y prospectiva, y eso, en buena medida, se lo debe a Borges. Podemos afirmar entonces que la relación de Menard con el Quijote de Cervantes es retroactiva, mientras que la de Vernier con los poetas simbolistas es prospectiva. Pero si le damos la vuelta al juego conceptual, podemos decir asimismo que la relación de Cervantes es prospectiva con respecto al Quijote de Menard, del mismo modo que lo es la de Menard con respecto a las obras de Gide, Unamuno, Valéry, etc. El Quijote de Cervantes ya contiene en potencia el Quijote de Menard, del mismo modo que Le voyage d'biver prefigura la obra de Lautréamont, Verlaine o Rimbaud, entre otros.

Según Pierre Bayard (2009) existen cuatro criterios para definir el plagio por anticipación: la similitud, la disimulación, la inversión temporal y la disonancia. Los dos primeros sirven también para definir el plagio clásico; los dos últimos son los que permiten diferenciar ambos tipos de plagio. No puede haber plagio por anticipación de un texto anterior. Además, y lo más importante, «el plagio por anticipación produce una sensación de

14. Cualquier texto que se precie es modificado por el paso del tiempo. Del mismo modo que Vernier plagia las obras de sus posteriores colegas, el Quijote de Cervantes emerge así como una especie de palimpsesto donde podemos intuir los rastros previos de la posterior escritura de Menard. "Casi podría decirse que Cervantes plagia por anticipación a Menard y solo con la obra del autor francés el Quijote alcanza su máxima potencialidad» (MOHÍÑo SÁNCHEZ 2004, 250). 
disonancia, de anacrónica extrañeza, como si la obra o el pasaje se encontraran en un lugar que no les corresponde» (en Martín Sánchez 2012, 126). Así, la disonancia ocasiona una perturbación y conduce al descubrimiento. Los procedimientos empleados por los escritores oulipianos desobedecen - paradójicamente a causa del uso de técnicas restrictivas- los lineales preceptos temporales. El hecho de que todo escritor que se precie crea a sus precursores implica una refutación del devenir establecido y provoca una alteración de la perspectiva ${ }^{15}$.

El texto de Perec contiene la tesis de la paulatina disolución de las huellas del pasado mediante la acumulación progresiva de huellas posteriores en el palimpsesto. La obra de Vernier desaparece como obra de Vernier, pero pervive diseminada bajo la firma de los «famosos impostores» que recogen los manuales de literatura, con lo que Perec parece resaltar, socarronamente, la irrelevancia de la autoría. En el fondo, el texto sugiere la imposibilidad última de comunicación; lo que resta es el silencio como irónica y cruel expresión del vacío. Degraël muere en un psiquiátrico y el único legado que deja son unas notas inconclusas sobre una investigación infructuosa. ¿Existió realmente el texto de Vernier o es producto de la mente alucinada de Degraël? La duda permanece irresoluble. Su obra, la investigación de Degraël, también encarada pero jamás realizada, refleja la misma incapacidad de comunicación que escondía el libro de su idolatrado Vernier. Surge así el vértigo de la interminable puesta en abismo. La imposibilidad del libro de Degraël es un reflejo de la imposibilidad del libro de Vernier. El mismo vértigo que contiene el texto de Perec en el nivel más próximo al lector. Finalmente, el único triunfo que puede anotarse Degraël es haber sembrado la duda sobre el canon implantado e inamovible de las academias, proponiendo la libertad transitoria de la literatura más allá de las caprichosas catalogaciones:

Pendant près de trente ans, Vincent Degraël s'efforça vainement de ressembler des preuves de l'existence de ce poète et de son ouvre. Lorsqu'il mourut, à l'hôpital psychiatrique de Verrières, quelques-uns de ses anciens élèves entreprirent de classer l'immense tas de documents et de manuscrits qu'il laissait: parmi eux figurait un épais registre relié de toile noir et dont l'étiquette portait, soigneusement calligraphié, Le voyage d'biver: les huit premières pages retraçaient l'histoire de ces vaines recherches; les trois cent quatre-vingt-douze autres étaient blanches (Perec 2013, 17).

15. "A decir verdad, para el Oulipo el tiempo no existe o, en todo caso, es reversible. Entendemos que lo oulipiano que existió antes del OulıPo sólo cobra sentido con el OulıPo. En realidad nuestra concepción no es demasiado original, es la de los historiadores, quienes consideran que el acontecimiento permite interpretar lo que lo ha precedido. Todo gran autor crea a sus propios antecesores» (MOHIÑo SÁNCHEZ 2004, 249). 
Por tanto, la narración sobre la investigación de Degraël modifica la visión hasta entonces aceptada sobre los poetas franceses de finales del XIX y contiene un guiño paródico a la crítica literaria: todos esos poetas aparecen allí como deudores de la obra de un autor genial y desconocido, Hugo Vernier. Años más tarde, ya fallecido Georges Perec, Jacques Roubaud se propuso la tarea de complementar la obra de su colega con una continuación, otra puesta en abismo, con una variación del tema que abriría las puertas a diferentes transformaciones del texto de Perec y conduciría la figura de Vernier por nuevos derroteros. El resultado fue Le voyage d'bier, al que siguieron diversas aportaciones de otros integrantes del OuLiPo: Marcel Bénabou, Michèle Audin, Jacques Bens, Harry Mathews, Ian Monk, Hervé Le Tellier y un largo etcétera. Todos esos textos se han editado, junto al relato de Perec, bajo el título de Le voyage d'hiver et ses suites (2013). Una aventura literaria que pretende homenajear y expandir en múltiples direcciones la ficción de Perec. Todo esto nos lleva a considerar la figura de Vernier como un desdoblamiento o una variante de Pierre Menard. Las secuelas de Roubaud y otros oulipianos interactúan con el texto de Perec del mismo modo que Une vie de Pierre Ménard lo hace con el relato de Borges. Igual que la novela de Lafon supone una desviación y un homenaje al cuento de Borges, los autores del OuLiPo encuentran un referente similar en la figura subterránea de Hugo Vernier, demiurgo y precursor soterrado de los grandes poetas franceses del XIX. Menard representa el aliento oculto tras las líneas de Valéry, de Gide, de Antonio Machado, del propio Borges; lo mismo que bajo las líneas del simbolismo subyace la imagen desenfocada de Vernier. Vernier es anterior a los poetas que lo plagian tres o cuatro décadas después. Menard es posterior a Cervantes, que lo plagia por anticipación. Del mismo modo, auspiciados por las ideas de potencialidad y recursividad, sus colegas oulipianos continúan la expansión del libro de Perec al infinito:

Libro de los libros que se hace con las frases de los otros, o que las contiene en origen. Ese libro maravilloso no anda lejos del que soñara Mallarmé. Por el lado lúdico cabría argumentar que Degraël escoge el libro de Hugo Vernier al azar de entre los de una nutrida biblioteca. Azar y biblioteca son términos que traen a Borges de la mano, y de la mano de éste precisamente es el «Pierre Menard, autor del Quijote», que contempla esta misma doble y disputada autoría que ocupa a Perec (Gamoneda 2004, 44).

Lo que en definitiva parece sugerir Perec en su breve nouvelle, como antes Borges y luego Lafon, es la función primordial de la lectura como reconocimiento. El texto es el resultado de la conjunción de ambas actividades: lectura y escritura. Podemos afirmar entonces que tanto Le voyage d'hiver como Une vie de Pierre Ménard suponen un paso más allá en la 
continua retroalimentación de la idea inicial de Borges. Escribe Legrand en una de sus rememoraciones del esquivo protagonista: «Ménard n'était pas seulement, pour moi l'auteur de tous les livres, il en était aussi le lecteur universel -il était, d'une certain manière, celui de qui provenaient tous les livres, et a qui tous les livres aboutissaient" (Lafon 2008, 174). Menard y Vernier reclaman la legitimidad del acto de leer sin el cual cualquier obra permanece huérfana. Si Vernier es el autor secreto de los poemas más importantes de la literatura francesa de la segunda mitad del siglo XIX, Menard es el autor clandestino de algunos de los textos franceses más relevantes del siglo Xx, como Le cimetière marin o Monsieur Teste, atribuidos a su amigo Paul Valéry, o Paludes, atribuido a su otro amigo André Gide. Menard, como Vernier en el siglo anterior, es «el artífice de uno de los proyectos de falsificación más ambiciosos de toda la historia literaria que consiste en crear colectivamente a un autor genial atribuyéndole una obra maestra que se impusiera al tesoro de la literatura universal» (Vecchio 2009, 8). Menard compendia escritura y lectura en un proceso fundamentado en la reciprocidad.

Menard y Vernier viven en la pura representación, habitan los intersticios entre las líneas "atribuidas" a otros, sin nada personal, sin identidad, falseados por la memoria de terceros: «Los grandes relatos de Borges giran sobre la incertidumbre del recuerdo personal, sobre la vida perdida y la experiencia artificial. La clave de este universo paranoico no es la amnesia y el olvido, sino la manipulación de la memoria y de la identidad» (Piglia 2014, 51). La obra de ambos personajes se diluye con ellos, quedando tan solo pequeños detalles desperdigados aquí y allá en una maraña de líneas apócrifas, como un puzle desperdigado en múltiples fragmentos, líneas dispersas en las obras de otros y ocultas bajo la firma de Rimbaud, Léon Bloy, Mallarmé o Catulle Mendès, en el caso de Vernier; Gide, Unamuno o Valéry, en el caso de Menard ${ }^{16}$. La diferencia entre ellos radica en que,

16. Otro guiño irónico: si las obras citadas fueron concebidas por estos singulares autores, Pierre Menard y Hugo Vernier, deducimos entonces que Verlaine, Gide, el mismo Cervantes, entre muchos otros, son impostores glorificados por un canon igualmente falso. En un segundo nivel tenemos a los narradores: Degraël, Legrand y el innominado del cuento de Borges, todos ellos, cuando menos, de dudosa confianza, artificios empleados por Borges, Perec y Lafon para provocar la vacilación y el juego de espejos. Luego está el rol del lector que se inmiscuye activamente en la ficción. Tácitamente se le está sugiriendo la posibilidad de que la obra que tiene entre las manos, ya sea "Pierre Menard, autor del Quijote", Un vie de Pierre Ménard o Le voyage d'hiver, sea igualmente fraudulenta. Y si continuamos tirando del hilo, ¿qué sucede con nosotros los lectores, de quién somos tan solo una mera invención? Al introducirnos en los entresijos de la ficción pasamos a formar parte de ella. 
si Vernier es el autor de un breve texto ignorado por la crítica, Menard representa la renuncia última a publicar, ya sea voluntariamente o movido por las circunstancias.

Se sugiere así una concepción de la literatura como repetición, como un eco rebotando desde Homero de un autor a otro. Una línea que encierra una secreta afinidad con otra línea oculta en la primera, que despierta un vago recuerdo sumergido en el palimpsesto y solo perceptible mediante ciertas condiciones de lectura. Entroncan así con el relato policial. Borges, Perec y Lafon crean un tipo de lector activo. La lectura otorga sentido al relato, despliega la polisemia del texto por distintos derroteros según la perspectiva. Lo que se le cuenta a ese lector no es confiable, hay que desentrañarlo quitando capa tras capa. Hay una realidad oculta bajo la superficie y deformada por la mistificación. La lectura provoca así una reencarnación, una especie de sortilegio que activa mecanismos hasta ese momento adormecidos. Ese lector desconfiado y paranoico que ha de resolver los enigmas proviene en buena medida del cuento policial de Allan Poe. Un buen ejemplo lo tenemos en la figura de Vincent Degraël, el personaje en la sombra de Le voyage d'hiver, el lector detective que Perec coloca en el centro de su ficción.

\section{CONCLUSIONES}

Perec plantea la posibilidad de que la literatura francesa posterior a 1864, supuestamente el año en que Hugo Vernier escribe Le voyage d'hiver, según las pesquisas de Vincent Dëgrael, se halle contenida en la obra de un autor ignorado anterior a esas obras canónicas. A la inversa de lo que ocurre con el Quijote de Menard, posterior al de Cervantes, al que modifica y enriquece por su nueva contextualización, la obra de Vernier prefigura y se dispersa en la posterior literatura francesa.

En Le voyage d'biver la potencialidad del texto se convierte en el objeto de la narración. La clave del relato está en su posibilidad de expansión y en su condición de obra abierta. Perec abre las puertas a una literatura autorreferencial que a un tiempo se pliega sobre sí misma y se despliega en los innumerables ámbitos que la circundan. Un diálogo interminable sobre las posibilidades de la literatura y sus mecanismos compositivos. Un relato que comparte con "Pierre Menard, autor del Quijote" y con Une vie de Pierre Ménard la imposibilidad de cualquier intento de parcelación. Y paradójicamente esa libertad que es su seña de identidad la obtiene a través del procedimiento marca de la casa de la literatura oulipiana, la restricción. Un texto que es un inmenso laberinto donde conviven otros textos. 
Como el Jardin des Plantes de Montpellier en Une vie de Pierre Ménard, una representación que contiene y arroja su propia representación y que disloca y confunde los niveles de ficción y realidad al borrar las fronteras que separan el libro de su afuera mediante la intromisión en la trama del propio proceso de lectura. En la novela de Lafon el Jardín es el símbolo de «un orden imaginario dado por el lenguaje» (Bogoya 2015, 202), trasunto en buena medida del relato "El jardín de senderos que se bifurcan", también de Ficciones. El Jardín aparece como un palimpsesto del que ha desaparecido hasta la más mínima huella del original: «El mundo de los libros y del Jardín son especulares, réplicas de una realidad ausente» (Bogoya 2015, 201). Es la reconstrucción de una representación, la idea inacabada de un original destruido. Del mismo modo el original de Hugo Vernier se ha esfumado para siempre, aunque pervive diseminado en las múltiples representaciones que el tiempo y el consenso de la crítica han trasmutado en originales y atribuido a sus célebres impostores.

La obra de Perec consolida la propuesta de una narrativa heterogénea basada en la ruptura de la linealidad temporal de las relaciones intertextuales, de las correspondencias entre hipotexto e hipertextos, una literatura donde confluyen simultáneamente en un mismo plano referencias a obras en principio distantes y distintas que convergen, gracias al novedoso enfoque oulipiano, en un punto que como el aleph de Borges nos permite escudriñar las secretas conexiones entre las obras y las analogías que sutilmente acontecen en el universo. Todo está en todo y cada manifestación es susceptible de mostrar múltiples apariencias. Le voyage d'hiver es un guiño tanto a "Pierre Menard, autor del Quijote" como a "Kafka y sus precursores». De ahí el concepto de "plagio por anticipación». Vernier y Menard se esconden del mundo y de la historia, o la historia se empeña en borrar las huellas de estos autores ignorados. Perec y Lafon, a través de los artificios constituidos por Dëgrael y Legrand, les restituyen la gloria escamoteada, pero, paradójicamente, lo hacen transformándolos en personajes fantasmagóricos, ocultando lo invisible en lo visible, provocando ese desdoblamiento entre lo inaccesible y lo manifiesto que, como escribió Foucault (1973) a propósito de ese otro misterioso escritor-personaje que fue Raymond Roussel, otorga su signo al lenguaje.

\section{REFERENCIAS}

AlAZRAKI, Jaime. 1984. "El texto como palimpsesto: lectura intertextual de Borges». Hispanic Review 52, 3: 281-302.

BAYARD, Pierre. 2009. Le plagiat par anticipation. Paris: Les Éditions de Minuit. 
Bogoya, Camilo. 2008. «Borges y Quignard: lectura y tradición». Variaciones Borges 26: 23-47.

Bogoya, Camilo. 2015. "De la crítica a la ficción: Michel Lafon y Pierrre Menard». En Una profunda necesidad en la ficción contemporánea: la recepción de Borges en la república mundial de las letras, editado por Brigitte Adriaensen, Meike Botterweg, Maarten Steenmeijer y Lies Wijterp, 193-206. Madrid: Iberoamericana.

Borges, Jorge Luis. 1989. Obras completas. 3 vols. Buenos Aires: Emecé.

Borges, Jorge Luis. 1992. Antología poética. Madrid: Alianza.

CAmarero, Jesús. 1988. "Aproximación al concepto de escritura en Georges Perec". Cuadernos de Investigación Filológica 14: 87-97.

Eco, Umberto. 2002. Sobre literatura. Traducido por Helena Lozano Miralles. Barcelona: RqueR.

Foucault, Michel. 1973. Raymond Roussel. Traducido por Patricio Canto. México: Siglo XXI.

Foucault, Michel. 2010. Las palabras y las cosas. Una arqueología de las ciencias bumanas. Traducido por Cecilia Frost. Buenos Aires: Siglo XXI.

GAMONEDA, Amelia. 2004. "La parada de los monstruos: sobre El viaje de invierno de Georges Perec». Revista de Libros 96: 44. Web.

GeneTte, Gerard. 1989. Palimpsestos: la literatura en segundo grado. Traducido por Cecilia Fernández Prieto. Madrid: Taurus.

GullLÉn, Claudio. 2005. Entre lo uno y lo diverso. Introducción a la literatura comparada. 2. ${ }^{a}$ ed. rev. y ampl. Barcelona: Tusquets.

Kristeva. Julia. 1969. Semiotiké. París: Seuil.

LAFON, Michel. 1990. Borges ou la réecriture. París: Seuil.

LAFON, Michel. 1993. "Borges y la modernidad». Revista Anthropos 142-143: 75-77.

LAFON, Michel. 2008. Une vie de Pierre Ménard. París: Gallimard.

LAFON, Michel. 2009. "Continuación de Menard». Variaciones Borges 28: 11-14.

LAFON, Michel. 2010. Una vida de Pierre Menard. Traducido por César Aira. Buenos Aires: Lumen.

LAFON, Michel. 2011a. "Borges y Francia, Francia y Borges». En Borges-Francia, editado por Magdalena Cámpora y Javier Roberto González, 21-34. Buenos Aires: Selectus.

LAFON, Michel. 2011b. «Menard (acaso sin quererlo). Écrire, traduire, ménardiser». En La realidad y el deseo. Tiponymie du découvrer en Amérique espagnole, editado por Carmen Val Julián, 331-340. Lyon: ENS Éditions.

MARTín Ruiz, Pablo. 2011. "La novela sin E y el secreto borgeano de Georges Perec». En Borges-Francia, editado por Magdalena Cámpora y Javier Roberto González, 193-202. Buenos Aires: Selectus.

MARTín SÁnchez, Pablo. 2012. El arte de combinar fragmentos. Prácticas hipertextuales en la literatura oulipiana (Raymond Queneau, Georges Perec, Italo Calvino, Jacque Roubaud). Tesis doctoral, Universidad de Granada.

MohíÑo SÁnchez, Pablo. 2004. "Plagiarios por anticipación: Georges Perec y la literatura española". En Actas del XV Congreso de la Asociación Internacional de 
Hispanistas: "Las dos orillas», editado por Beatriz Mariscal y María Teresa Miaja de la Peña, 3: 247-260. México: Fondo de Cultura Económica.

Oulipo (Nöel Arnaud, Marcel Bénabou, Jacques Bens, Claude Berge, Jacques Duchateau, Jean-Pierre Enard, Luc Étienne, Paul Fournel, Latis, François Le Lionnais, Jean Lescure, Georges Perec, Raymond Queneau, Jean Queval, Jacques Roubaud et d'Albert-Marie Schmidt). 1973. La littérature potentielle: Créations, Re-créations, Récréations. París: Gallimard.

PAuls, Alan. 2004. El factor Borges. Barcelona: Anagrama.

PAuls, Alan. 2010. "La herencia Borges». Variaciones Borges 29: 177-188.

Perec, Georges. 1972. Les Revenentes. París: Julliard.

Perec, Georges. 1989. La vie mode d'emploi. París: Le livre de poche.

PEREC, Georges. 1990. La disparition. París: Gallimard.

PEREC, Georges. 2006. El viaje de invierno. Traducido por Juan Barja. Madrid: Abada.

PEREC, Georges. 2008. El gabinete de un aficionado. Traducido por Menene Gras Balaguer. Barcelona: Anagrama.

Perec, Georges. 2013. Le voyage d'hiver \& ses suites. París: Seuil.

Perec, Georges. 2105. W ou le souvenir d'enfance. París: Gallimard.

Pérez Pérez, Manuel J. 2017. Pierre Menard y el personaje en las biografias imaginarias (Lafon, Wilcock, Borges y Schwob). Tesis doctoral. Universidad de Sevilla.

PÉREz PÉREz, Manuel. J. 2019. «Resonancias de Pierre Menard en un cuento de Marco Denevi». Variaciones Borges 47: 173-191.

Piglia, Ricardo. 2014. Formas breves. Barcelona: Debolsillo.

RIERA, Gabriel. 2005. "Repetición, libro y anti-libro. Reflexiones sobre la intertextualidad en Borges». Variaciones Borges 20: 215-230.

TAccA, Óscar. 1998. “Quién es Pierre Menard?. En Actas del Tercer Congreso Internacional de la Asociación de Cervantistas, editado por Antonio Pablo Bernat Vistarini, 721-735. Palma: Universitat de les Illes Balears.

Vecchio, Diego. 2009. "La ficción como falsificación: Michel Lafon, Une vie de Pierre Ménard". Variaciones Borges 28: 1-10.

Wilcock, Juan Rodolfo. 1972. La sinagoga degli iconoclasti. Milán: Adelphi.

Wilcock, Juan Rodolfo. 1999. La sinagoga de los iconoclastas. Traducido por Joaquín Jordá. Barcelona: Anagrama. 
